\title{
Frequency potentiation and postextrasystolic potentiation in patients with and without coronary arterial disease
}

\author{
F. Schwarz, J. Thormann, and B. Winkler \\ with the technical assistance of B. Foelkel \\ From the Kerckhoff-Klinik, Bad Nauheim, Germany
}

Frequency potentiation and postextrasystolic potentiation of myocardial contractility were induced in 17 patients found not to have cardiac disease (group $I$ ) and in Io patients with coronary arterial disease (group 2). Atrial stimulation was performed starting at a rate of $110 /$ min and going up to 200/min (frequency potentiation). Single, premature ventricular beats with decreasing coupling intervals were induced every fifteenth beat during basal atrial stimulation at 125/min, after which compensatory pauses were provided (postextrasystolic potentiation). The time derivative of left ventricular pressure (dp/dt) was used as an index of contractility. With increasing heart rate $d p / d t$ max was augmented equally, in both groups of patients, by frequency increases and premature beats (the coupling interval of the extrasystole being expressed as heart rate). $d p / d t$ min and left ventricular systolic pressure remained unchanged while left ventricular end-diastolic pressure decreased in both groups of patients with the two forms of potentiation. It was concluded that both these forms of potentiation have the same augmenting effect on myocardial contractility. Shortening the coupling intervals of premature beats caused a decrease in left ventricular end-diastolic pressure, suggesting that the Frank-Starling mechanism was not involved in postextrasystolic potentiation. Patients with coronary arterial disease had lower values of $d p / d t$ max, $d p / d t$ min, and higher values of left ventricular end-diastolic pressure during rest and stimulation procedures, while the systolic pressures equalled those in the control group. Though individual case values from the healthy and diseased hearts might be similar, it was only under the stress of potentiation that the true state of contractility was made apparent. Impairment of $d p / d t$ min was not found without an impairment of $d p / d t$ max in the presence of myocardial ischaemia.

It has been shown that myocardial contractile function during rest and isometric exercise can be characterized by contractility indices (Krayenbuehl et al., 1973; Hugenholtz et al., 1970). In evaluating patients with coronary arterial disease, depressed contractility was found, but myocardial contractility during rest was not diminished in all cases, so that the differentiation between normal and diseased hearts was often impossible (Hugenholtz et al., 1970). For a more diagnostic characterization, it was recently suggested that the measurement of the peak negative value of the time derivative of left ventricular pressure (dp/dt min) be used (McLaurin, Rolett, and Grossman, 1973). In the presence of pacing-induced ischaemia, a reduced $\mathrm{dp} / \mathrm{dt} \mathrm{min}$ was found while dp/dt max was normal or augmented, indicating an impairment in ventricular

Received 26 July 1974• relaxation. Consequently, it was proposed that $\mathrm{dp} / \mathrm{dt}$ min might be a better index than dp/dt max in detecting myocardial ischaemia. The purposes of this study were to establish whether inotropic stress resulting from frequency potentiation (Koch-Weser, 1963) or postextrasystolic potentiation was useful in separating patients with coronary arterial disease from patients without heart disease; secondly, to investigate which form of potentiation was more effective; and thirdly, to discover whether myocardial ischaemia makes isolated impairment of ventricular relaxation evident (McLaurin et al., 1973).

\section{Methods}

\section{A) Patients}

Twenty-seven patients referred for assessment of suspected heart disease were studied. Seventeen of these (I4 to 53 years; mean 29 years) who on clinical examina- 
TABLE Clinical and routine catheterization data of all patients

\begin{tabular}{|c|c|c|c|c|c|c|c|c|c|}
\hline $\begin{array}{l}\text { Case } \\
\text { No. }\end{array}$ & $\begin{array}{l}\text { Age } \\
(y r)\end{array}$ & Sex & \multicolumn{3}{|c|}{ Clinical diagnosis } & $\begin{array}{l}\text { Right heart } \\
\text { catheter }\end{array}$ & \multicolumn{2}{|c|}{$\begin{array}{l}L V E D P(k P a) \\
R\end{array}$} & $\begin{array}{l}\text { Coronary arteriography and } \\
\text { ventriculography }\end{array}$ \\
\hline \multicolumn{10}{|c|}{ Patients without heart disease (group I). } \\
\hline $\mathbf{I}$ & 16 & $\mathbf{F}$ & \multirow{2}{*}{\multicolumn{3}{|c|}{$\begin{array}{l}\text { Neurocirc. asthenia } \\
\text { Neurocirc. asthenia }\end{array}$}} & WNL & 0.9 & 0.9 & \\
\hline 2 & 38 & $\mathbf{M}$ & & & & WNL & 0.5 & 0.7 & \\
\hline 3 & 14 & $\mathbf{M}$ & \multicolumn{3}{|c|}{ " } & WNL & 0.5 & I.I & \\
\hline 4 & 14 & $\mathbf{M}$ & \multicolumn{3}{|c|}{ " } & WNL & 0.1 & 0.8 & \\
\hline 5 & 26 & $\mathbf{M}$ & \multicolumn{3}{|c|}{ " } & WNL & 0.5 & 1.9 & \\
\hline 6 & 44 & $\mathbf{M}$ & \multicolumn{3}{|c|}{ " } & & 0.8 & 0.5 & \\
\hline 7 & 19 & $\mathbf{M}$ & \multicolumn{3}{|c|}{ " } & $\begin{array}{l}\text { WNL } \\
(\mathrm{R}+\mathrm{E})\end{array}$ & 0.7 & 0.5 & \\
\hline 8 & 17 & $\mathbf{M}$ & ” & \multicolumn{2}{|c|}{ 》 } & $\begin{array}{l}\text { WNL } \\
(R+E)\end{array}$ & 0.8 & 2.3 & \\
\hline 9 & 17 & $\mathbf{M}$ & " & \multicolumn{2}{|c|}{ " } & WNL & 0.8 & 0.4 & \\
\hline 10 & 25 & $\mathbf{M}$ & ” & \multicolumn{2}{|c|}{ " } & WNL & 0.4 & 0.8 & \\
\hline II & 32 & $\mathbf{M}$ & ” & \multicolumn{2}{|c|}{$"$} & WNL & 0.5 & 1.3 & \\
\hline 12 & 37 & $\mathbf{F}$ & " & \multicolumn{2}{|c|}{ " } & WNL & I.I & 1.5 & \\
\hline 13 & 45 & $\mathbf{M}$ & \multicolumn{3}{|c|}{$\begin{array}{l}\text { Nonspecific praecordial } \\
\text { pain }\end{array}$} & & I.5 & 1.5 & WNL \\
\hline 14 & 38 & $\mathbf{M}$ & \multicolumn{3}{|c|}{$\begin{array}{l}\text { Nonspecific praecordial } \\
\text { pain }\end{array}$} & & I.6 & 2.1 & WNL \\
\hline 15 & 38 & $\mathbf{M}$ & \multicolumn{3}{|c|}{$\begin{array}{l}\text { Nonspecific praecordial } \\
\text { pain }\end{array}$} & $\begin{array}{l}\text { WNL } \\
(\mathrm{R}+\mathrm{E})\end{array}$ & 0 & & WNL \\
\hline 16 & 45 & $\mathbf{F}$ & \multicolumn{3}{|c|}{ Neurocirc. asthenia } & $\begin{array}{l}\text { WNL } \\
(\mathrm{R}+\mathrm{E})\end{array}$ & 0.4 & I.I & \\
\hline 17 & 53 & $\mathbf{M}$ & \multicolumn{3}{|c|}{$\begin{array}{l}\text { Nonspecific praecordial } \\
\text { pain }\end{array}$} & WNL & 0.5 & 0.8 & WNL \\
\hline \multicolumn{10}{|c|}{ Patients with coronary arterial disease (group 2) } \\
\hline 18 & 50 & $\mathbf{M}$ & \multicolumn{3}{|c|}{ Coronary arterial disease } & & 0.2 & 1.3 & I v.d. WNL \\
\hline 19 & 47 & $\mathbf{M}$ & 川 & & 川 & & 1.2 & 2.7 & $\begin{array}{l}\text { I v.d. anterior } \\
\text { aneurysm }\end{array}$ \\
\hline 20 & 44 & $\mathbf{M}$ & " & " & ” & $\begin{array}{l}\text { WNL } \\
(\mathrm{R})\end{array}$ & 0.7 & 2.7 & $\begin{array}{l}\text { I v.d. anterior } \\
\text { aneurysm }\end{array}$ \\
\hline $2 \mathbf{I}$ & 52 & $\mathbf{M}$ & 川 & ” & ” & & $5 \cdot 3$ & 5.7 & $\begin{array}{l}3 \mathrm{v} . \mathrm{d} . \text { anterior } \\
\text { aneurysm }\end{array}$ \\
\hline 22 & 54 & $\mathbf{F}$ & " & ” & ” & & 0.9 & 2.5 & 3 v.d. WNL \\
\hline 23 & 53 & $\mathbf{M}$ & " & " & $"$ & $\begin{array}{r}\text { Raised PA } \\
\text { pressure }\end{array}$ & 2.5 & 2.7 & $\begin{array}{l}2 \text { v.d. anterior } \\
\text { aneurysm }\end{array}$ \\
\hline 24 & 52 & $\mathbf{M}$ & " & " & " & $\begin{array}{l}\text { WNL } \\
(\mathbf{R})\end{array}$ & 0.7 & 2.0 & I v.d. WNL \\
\hline 25 & 47 & $\mathbf{M}$ & 川 & 川 & " & & 3.5 & 8.0 & $\begin{array}{l}\text { I v.d. anterior } \\
\text { aneurysm }\end{array}$ \\
\hline 26 & 44 & $\mathbf{M}$ & » & ” & " & & 0.8 & 2.7 & $\begin{array}{l}\text { I v.d. anterior } \\
\text { aneurysm }\end{array}$ \\
\hline 27 & $6 I$ & $\mathbf{M}$ & ” & ” & " & $\begin{array}{l}\text { WNL } \\
\text { (R) }\end{array}$ & 0.9 & 1.9 & $\begin{array}{l}\text { I v.d. anterior } \\
\text { dyskinesis }\end{array}$ \\
\hline
\end{tabular}

CAD, coronary arterial disease; LVEDP, left ventricular end-diastolic pressure; WNL, within normal limits; $R$, rest; $P$, after atrial stimulation ( $>$ IO $s$ averaged); $R+E$, during rest and ergometry; $1-3$ v.d., no. of vessels diseased (coronary arterial narrowing over 50 per cent). Conversion from $S I$ units to traditional units: I $\mathrm{kPa} \simeq 7.5 \mathrm{mmHg}$.

tion and routine catheterization data had no heart disease, were placed in group I. Ten patients with angiographically-proven coronary arterial disease were placed in group 2; they had a mean age of 51 (range 44 to 61 years) and were off medication at least 5 days before catheterization. The patients were informed of the nature and purpose of the investigation and consented to its performance. Clinical and routine catheterization data are presented in the Table.

\section{B) Haemodynamic measurements}

After routine catheterization, two pacing electrodes were placed for pacing studies: one in a high lateral atrial position and the other at the apex of the right ventricle. Stimulation was performed using a step-bystep regulating stimulator and a second stimulating system which allowed the coupling of single stimuli with varied coupling times. Left ventricular pressure 
and its time derivative $(\mathrm{dp} / \mathrm{dt})$ were obtained by a $5 \mathrm{~F}$ Millar-type catheter-tip manometer (via the femoral artery) and a resistance-capacitance differentiating circuit with a time constant of $0.5 \mathrm{~ms}$ and an output linearly proportional to the input frequency, within 5 per cent, up to a rated maximal frequency of $75 \mathrm{~Hz}$. Left ventricular end-diastolic pressure was amplified and limited by an extra channel. The lowest diastolic pressure was used as the zero reference level. All variables, including one electrocardiographic lead, were recorded on an Electronics for Medicine recorder with a paper speed of $50-100 \mathrm{~mm} / \mathrm{s}$. Aortic pressure was measured during sinus rhythm only because earlier studies have shown that mean arterial pressure does not change during pacing and stimulation procedures (Linhart, I972; Parker, Khaja, and Case, I97I).

\section{C) Stimulating studies}

Ten minutes after the placement of catheters, atrial stimulation was performed beginning at $\mathrm{rr} / \mathrm{min}$. After each minute the frequency was increased by $15 / \mathrm{min}$ until a maximal frequency of $200 / \mathrm{min}$ was reached or seconddegree AV block occurred. Atrial pacing was then carried out with a basic frequency of $125 / \mathrm{min}$, and premature ventricular contractions with varying coupling intervals, were stimulated after each fifteenth contraction. The coupling interval was decreased by steps of $20 \mathrm{~ms}$ until no further electrical response could be detected. A compensatory pause was provided after the premature ventricular contractions so that the overall heart rate remained constant. The maximal compensatory pause after premature ventricular contractions was about 700 $\mathrm{ms}$, equal to a rate of $86 / \mathrm{min}$. (Taking a basic heart rate of $125 / \mathrm{min}=480 \mathrm{~ms}$ cycle length, with a coupling interval of $260 \mathrm{~ms}$, the compensatory pause is $700 \mathrm{~ms}$.) This frequency was similar to the frequency ranges of sinus rhythm, so that in each case it could be confirmed that $\mathrm{dp} / \mathrm{dt}$ had reached its maximum before aortic valve opening. Each interval was tested at least twice and the mean taken. Basic atrial pacing (stimulation) at $125 / \mathrm{min}$ was chosen because (I) we wanted equal conditions for testing in both groups of patients, and several patients with neurocirculatory asthenia had resting heart rates of over $100 / \mathrm{min}$, and (2) with long compensatory pauses, $\mathrm{dp} / \mathrm{dt}$ max may reach its maximum after aortic valve opening. Finally, the basic atrial pacing rate was increased by steps of $15 / \mathrm{min}$ (each rate lasting one $\mathrm{min}$ ) while the coupling interval of one extrasystole was fixed. This interval was selected so that optimal potentiation could be obtained. Atrial pacing alone and atrial pacing with varied premature ventricular contractions were performed on patients with coronary arterial disease. Atrial pacing was interrupted if angina pectoris was noted or if $\mathrm{dp} / \mathrm{dt}$ max decreased abruptly. Cases 18 and 27 did not develop angina during pacing.

Analysis of regression was obtained by an IBM computer using raw data and mean values in all instances. The coupling interval of the premature ventricular contraction was expressed as heart rate in order to arrive at a linear relation, since relating coupling intervals in $\mathrm{ms}$ to dp/dt results in hyperbolas which are difficult to com- pare statistically. The regression lines were compared for regression coefficients and position of slopes. Comparisons of the pacing and stimulation procedures within each group were calculated, always using data of the same patients. Comparisons of different patients were made between groups $I$ and 2 .

\section{Results}

\section{Atrial stimulation (frequency potentiation)}

Patients without heart disease (group I) showed a linear augmentation of $\mathrm{dp} / \mathrm{dt} \max$ as the heart rate increased ( $r=0.68, P<0.001$, Fig. Ia). Dp/dt min (Fig. 2a), left ventricular end-diastolic pressure (Fig. 3a) and left ventricular systolic pressure (mean $=116 \pm 3 \mathrm{mmHg}$ ) did not change with increasing heart rate.

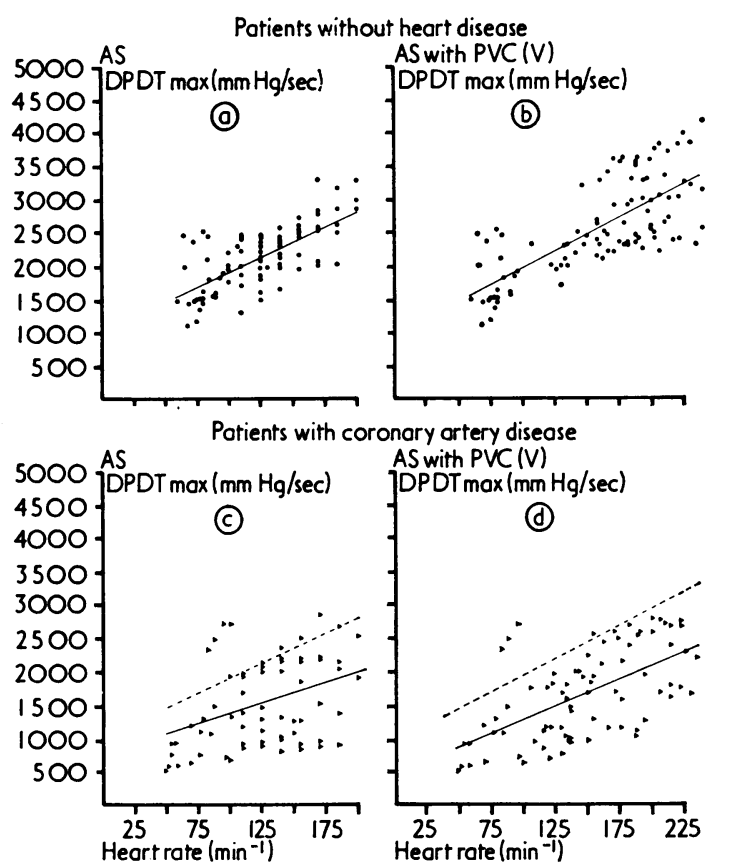

FIG. I Relation of heart rate to $d p / d t$ max in patients without heart disease $(a+b)$ and with coronary arterial disease $(c+d)$. 'Heart rate' in panels $b$ and $d$ denotes the varied coupling intervals of the premature ventricular contractions (PVC). Differences in the relations of frequency and prematurity potentiation exist between the groups of patients but not within a single group. Dotted lines $(c+d)$ represent, for comparison, the relation of patients without heart disease. Note that control values are included in all graphs. $A S=$ atrial stimulation (pacing); $A S$ with $P V C(V)=$ atrial stimulation (I25/min) with premature ventricular contractions. Measurements made during spontaneous sinus rhythm before pacing are included. 


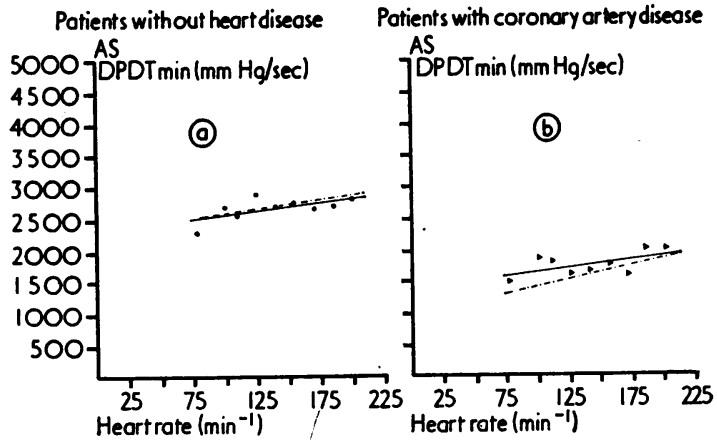

FIG. 2 Relation of heart rate to $d p / d t$ min in patients without heart disease (a) and in patients with coronary arterial disease (b). Uninterrupted lines show relations obtained during atrial stimulation $(A S)$; interrupted lines during prematurity potentiation. Differences in the relations of frequency and prematurity potentiation exist between the groups of patients but not within a single group. There are no changes in $d p / d t$ min with increase in 'heart rate'.

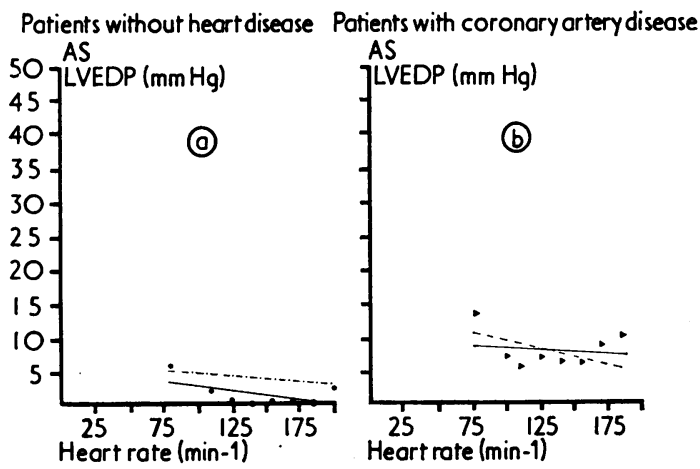

FIG. 3 Relation of heart rate to left ventricular enddiastolic pressure (LVEDP) in patients without heart disease (a) and with coronary artery disease (b). Uninterrupted lines show relations obtained during atrial stimulation ( $A S)$; interrupted lines during prematurity potentiation. Differences in the relations of frequency and prematurity potentiation exist between the groups of patients, but not within a single group. With increasing heart rate, the LVEDP remains equal or decreases.

Patients with coronary arterial disease (group 2) also revealed a linear augmentation of $\mathrm{dp} / \mathrm{dt} \max$ with increasing heart rate $(r=0.36, P<0.01$, Fig. Ic). dp/dt min remained unchanged (Fig. 2b), as did left ventricular systolic pressure (mean $=122 \pm$ $4 \mathrm{mmHg}$ ) and left ventricular end-diastolic pressure (Fig. 3b).
Comparison of the groups of patients revealed no difference in the slopes for the regression coefficients, but significant differences in position: in patients with coronary arterial disease, $\mathrm{dp} / \mathrm{dt} \max$ and $\mathrm{dp} / \mathrm{dt}$ min were lower for all heart rates. Left ventricular end-diastolic pressure was raised for all heart rates in this group. Left ventricular systolic pressures in the two groups were nearly equal.

Atrial pacing with varied ventricular premature beats (postextrasystolic potentiation)

In patients without heart disease there was a linear augmentation of $\mathrm{dp} / \mathrm{dt} \max$ of the postextrasystolic beat as the coupling time was decreased (expressed as increasing heart rate, Fig. Ib). The regression coefficient was 0.73 . dp/dt min remained unchanged (Fig. 2a), as did left ventricular systolic pressure (mean $121 \pm 2 \mathrm{mmHg}$ ). Left ventricular end-diastolic pressure decreased significantly with increasing heart rate (Fig. 3a), meaning that the left ventricular end-diastolic pressure of the potentiated beat was lower with decreased coupling time.

Patients with coronary arterial disease showed a linear augmentation of $\mathrm{dp} / \mathrm{dt} \max$ while heart rate increased (Fig. Id). The regression coefficient was $\mathbf{r}=0.60$. Neither dp/dt min (Fig. 2b) nor left ventricular systolic pressure (mean $=122 \pm 3 \mathrm{mmHg}$ ) changed. Left ventricular end-diastolic pressure of the potentiated beat was significantly lower with increasing heart rate (Fig. $3 \mathrm{~b}$ ).

Comparison of the groups of patients showed no difference in regression coefficients, but differences of position: $\mathrm{dp} / \mathrm{dt} \max$ and $\mathrm{dp} / \mathrm{dt} \min$ were significantly lower in patients with coronary arterial disease and left ventricular end-diastolic pressure was higher. Left ventricular systolic pressures were again nearly equal.

Comparison of frequency potentiation and postextrasystolic potentiation

No differences within each group of patients were shown when the effects of premature ventricular contractions (expressed as heart rate) were compared to the effects of atrial pacing, taking dp/dt $\max , \mathrm{dp} / \mathrm{dt} \mathrm{min}$, and left ventricular end-diastolic pressure into consideration.

Variation of basal frequency with fixed premature ventricular contractions

Basal frequency changes (125-200/min) with an optimally fixed, single premature ventricular contraction in patients without heart disease showed

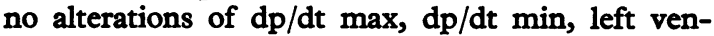
tricular systolic pressure or the left ventricular enddiastolic pressure of the potentiated beat. Post- 
extrasystolic potentiation, therefore, was not affected by basal frequency changes.

\section{Discussion}

Studies in animals and in man have shown that the time derivative of left ventricular pressure, used as an empirical index, is very useful as a reflection of myocardial contractility (Patterson, Kent, and Peirce, 1972; Mason, 1969; Fisher et al., 1967). Other indices such as $\mathrm{V}$ max or V pm provide little additional information (Patterson et al., 1972; Raff, Stauber, and Kissling, 1974). For clinical purposes, $\mathrm{dp} / \mathrm{dt}$, easily obtained from catheter tip manometers, is reliable except in cases of significant mitral or aortic valve lesions and extremely low diastolic aortic pressures. None of the patients in this study presented these conditions. $\mathrm{dp} / \mathrm{dt}$ is more affected by changes in contractility than by alterations in preload (Patterson et al., 1972) and afterload (Fisher et al., 1967; Schaper, Lewi, and Jagenau, 1965). The reproducibility of this index is excellent (Patterson et al., 1972). In our studies an increase in left ventricular end-diastolic pressure never occurred during pacing procedures, so the alterations of $\mathrm{dp} / \mathrm{dt} \max$ were, therefore, viewed as true increases of contractility. Significant changes in afterload during pacing studies were not expected (Linhart, 1972; Parker et al., 1971).

When frequency potentiation and postextrasystolic potentiation were related to heart rate, it was extraordinary to find an equal augmentation of $\mathrm{dp} /$ dt max in non-cardiac patients and in those with coronary artery disease. There were also no differences when $\mathrm{dp} / \mathrm{dt} \mathrm{min}$, left ventricular systolic pressure, and left ventricular end-diastolic pressure were compared. It had been concluded from results obtained in isolated papillary muscle preparations that there was a fundamental difference in the two potentiating mechanisms (Kilz et al., 1968; KochWeser, 1966). This may be explained by the lower frequencies used in muscle preparations, and by species differences. On the other hand, the results obtained from our non-cardiac patient studies, which showed (with both forms of potentiation) a $\mathrm{dp} / \mathrm{dt}$ max augmentation of nearly 100 per cent, correlated well, when compared at a rate of $200 / \mathrm{min}$, with the results obtained in animal experiments (Fisher et al., 1967; Takada et al., 1970). It is apparent from Fig. I, panels a and b, however, that the highest possible values of $\mathrm{dp} / \mathrm{dt} \max$ were reached with postextrasystolic potentiation simply because single premature ventricular contractions at short coupling intervals could be interspaced with- out difficulty, whereas continuous atrial pacing at rates over $200 / \mathrm{min}$ could be dangerous.

Another interesting finding was that the left ventricular end-diastolic pressure of the potentiated beat was significantly lower with a shorter coupling time. It could be speculated that postextrasystolic potentiation tends to change diastolic compliance of the potentiated beat as well as contractile function. Similar findings have been described in kitten papillary muscle preparations (Koch-Weser, 1966) and in dog experiments (Ross et al., 1965). These arguments support the contention that postextrasystolic potentiation is not mediated by the FrankStarling mechanism, but by an activation process of unknown origin.

During changes of the stimulated atrial rate (125-200/ $\mathrm{min}$ ) with fixed, coupled premature ventricular contractions there was no significant change in $\mathrm{dp} / \mathrm{dt} \max$ and other variables. Consequently, the time interval of the postextrasystolic pause was of minor importance.

In patients with coronary arterial disease, a diminished level of $\mathrm{dp} / \mathrm{dt} \max$ during control and the entire tested frequency range was found (Fig. I). However, the results obtained in individual coronary arterial disease patients without ventricular dysfunction in the ventriculogram and without ischaemia during the investigation showed no depression of contractility during pacing stress (Fig. 4). These observations corresponded well with those of others who, using $\mathrm{V}$ max, had also found a great scatter of values in patients with coronary arterial disease during isometric exercise (Krayenbuehl et al., 1973) and pacing (Graber et al., 1972). Several patients with coronary arterial disease in both the aforementioned studies had values in the uppernormal range. We consider $\mathrm{dp} / \mathrm{dt}$ max during pacing to be quantitatively reflective of the situation in coronary arterial disease. Extensive coronary arterial disease is characterized by a lack of potentiation, while the heart with a minor degree of coronary arterial disease cannot be distinguished from a healthy heart since it shows no depressed contractility during pacing stress.

A decrease in $\mathrm{dp} / \mathrm{dt}$ min without a respective decrease in dp/dt max, as has been described (McLaurin et al., 1973), was not seen in our patients with coronary arterial disease during pacing-induced myocardial ischaemia (see Fig. I, 2). Thus, we cannot support the hypothesis that relaxation is more sensitive to ischaemia than contraction. The difference between our results and McLaurin et al.'s (1973) may be attributed to the different types of patients investigated; in his group 2, two of seven patients had aortic stenosis. If these patients had 


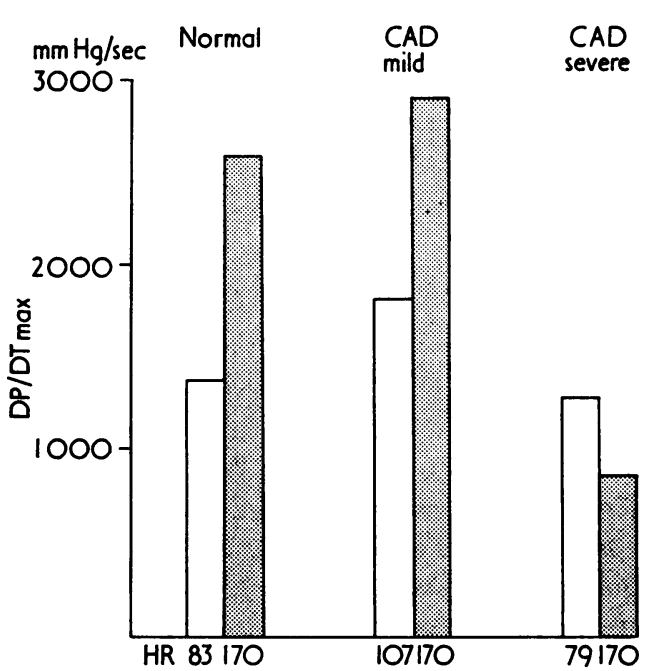

FIG. 4 The $d p / d t$ max values of 3 separate patients at rest and at a pacing rate of $170 /$ min are shown. The rest values of all 3 patients are comparable. At a pacing rate of $170 /$ min the patient with mild coronary arterial disease $(C A D)$ shows no difference from the normal patient, whereas the patient with severe $C A D$ shows a decrease in $d p / d t$ max. Apparently, pacing 'unmasks' impaired myocardial contractility in the patient with severe coronary arterial disease.

been excluded, statistical significance would no longer have been achieved.

\section{References}

Fisher, V. J., Lee, R. J., Marlon, A. M., and Kavaler, F. (1967). Paired electrical stimulation on the maximal contractile response of the ventricle. Circulation Research, 20, 520.

Graber, J. D., Conti, C. R., Lappe, D. L., and Ross, R. S. (1972). Effect of pacing-induced tachycardia and myocardial ischemia on ventricular pressure-velocity relationships in man. Circulation, 46, 74.

Hugenholtz, P. G., Ellison, R. C., Urschel, C. W., Mirsky, I., and Sonnenblick, E. H. (1970). Myocardial force-velocity relationships in clinical heart disease. Circulation, 41, 191.
Kilz, U., Schaefer, J., Schwarzkopf, H. J., and von Zwieten, P. A. (1968). Einfluss von Hexobarbital-Natrium und Carbachol auf die Frequenz- und postextrasystolische Potenzierung des isolierten Meerschweinchenvorhofes. Pflügers Archiv für die gesamte Physiologie, 304, 203.

Koch-Weser, J. (1963). Effect of rate changes on strength and time course of contraction of papillary muscle. American fournal of Physiology, 204, 45 I.

Koch-Weser, J. (1966). Potentiation of myocardial contractility by continual premature extra-activations. Circulation Research, 18, 330.

Krayenbuehl, H. P., Rutishauser, W., Wirz, P., Amende, I., and Mehmel, H. (1973). High fidelity left ventricular pressure measurements for the assessment of cardiac contractility in man. American fournal of Cardiology, 31, 415.

Linhart, J. W. (1972). Atrial pacing in coronary artery disease, including preinfarction angina and postoperative studies. American fournal of Cardiology, 30, 603.

McLaurin, L. P., Rolett, E. L., and Grossman, W. (1973). Impaired left ventricular relaxation during pacinginduced ischemia. American fournal of Cardiology, 32, 751.

Mason, D. T. (1969). Usefulness and limitations of the rate of rise of intraventricular pressure (dp/dt) in the evaluation of myocardial contractility in man. American fournal of Cardiology, 23, 516.

Parker, J. O., Khaja, F., and Case, R. B. (197I). Analysis of left ventricular function by atrial pacing. Circulation, 43, 241.

Patterson, R. E., Kent, B. B., and Peirce, E. C. (1972). A comparison of empiric contractile indices in intact dogs. Cardiology, 57, 277.

Raff, U., Stauber, W., and Kissling, G. (1974). Die Aussagekraft verschiedener Kontraktilitätsindices beim Herzen in situ. Basic Research in Cardiology, 69, 58.

Ross, J., Jr., Sonnenblick, E. H., Kaiser, G. A., Frommer, P. L., and Braunwald, E. (1965). Electroaugmentation of ventricular performance and oxygen consumption by repetitive application of paired electrical stimuli. Circulation Research, 16, 332.

Schaper, W. K. A., Lewi, P., and Jagenau, A. H. M. (1965). The determinants of the rate of change of the left ventricular pressure (dp/dt). Archiv für Kreislaufforschung, 46, 27.

Takada, H., Takeuchi, S., Ando, K., Kaito, A., Yoshida, S., Hisada, S., and Mizuno, Y. (1970). Experimental studies on myocardial contractility and hemodynamics in extrasystoles. Fapanese Circulation fournal, 34, 419.

Requests for reprints to Dr. F. Schwarz, KerckhoffKlinik, Benekestrasse 6-8, D-635 Bad Nauheim, Germany. 